\title{
Pengaruh sifat mekanik dari fraksi volume komposit berpenguat serat tandan kosong kelapa sawit
}

\author{
Ady Setiawan $^{1 *}$, Daryono ${ }^{2}$, Topan Prihantoro ${ }^{3}$ \\ 1Jurusan Teknik Mesin, Prodi Teknologi mesin, Politeknik Negeri Pontianak Kampus \\ Kabupaten Sanggau \\ Jl. Sabang Merah, Bunut, Kapuas, Kabupaten Sanggau, Kalimantan Barat 78561 \\ 2Jurusan Teknik Mesin, Prodi Teknologi mesin, Politeknik Negeri Pontianak \\ Jl. Jenderal Ahmad Yani, Bansir Laut, Kec. Pontianak Tenggara, Kota Pontianak, \\ Kalimantan Barat 78124 \\ 3Jurusan Teknik Mesin, Prodi Teknik mesin, Politeknik Negeri Pontianak \\ Jl. Jenderal Ahmad Yani, Bansir Laut, Kec. Pontianak Tenggara, Kota Pontianak, \\ Kalimantan Barat 78124 \\ *Corresponding author: Adys62409@gmail.com
}

\begin{abstract}
The palm oil industry is known as oil palm empty fruit bunches. Currently, the development of material technology is growing rapidly. Various materials have been continuously researched to get better materials, namely matrix composites. The purpose of the study was to determine the effect of the volume fraction of oil palm empty fruit bunches fiber with mechanical properties, type of fracture and to find the best volume fraction composition. The research method used was the compression of $4 \%, 6 \%$ and $8 \%$ volume fractions. The tests were carried out by the Pontianak State Polytechnic Campus, Kab. Sanggau. Research has shown that with the increase in the volume of the fiber fraction, the tensile strength of the fiber fraction volume specimens is $4 \%, 6 \%$, and $8 \%$, respectively, $43.20 \mathrm{MPa}, 65.00 \mathrm{MPa}$, and $86.12 \mathrm{MPa}$. The strain values for the volume fractions of $4 \%, 6 \%$, and $8 \%$, respectively, are $11.80 \%, 4.07 \%$ and $4.68 \%$ and without fiber $6.47 \%$ the effect of strain on the TKSS fiber-reinforced composite is on the volume fraction. $4 \%$ i.e. $11.80 \%$. Oil palm empty fruit bunch fiber-reinforced composites can be enhanced by strengthening the composites. The type of fracture that occurs in the polyester resin specimen and the EFB fiber reinforced composite is brittle fracture. The fiber volume fraction is $6 \%$ which has the largest modulus of elasticity with a value of $21.04 \mathrm{MPa}$. These results affect the volume of $4 \%$ and $8 \%$ fiber fractions, $2.66 \%$, and $21.48 \%$, while without oil palm empty fruit bunches it is $8.79 \mathrm{MPa}$.
\end{abstract}

Keywords: Polyster resin, composite, palm empty fruit bunch fiber, tensile test

\begin{abstract}
Abstrak
Industri kelapa sawit yang di kenal sebagai tandan kosong kelapa sawit. Saat ini perkembangan teknologi bahan semakin pesat. Berbagai bahan telah penelitian berlanjut untuk mendapatkan matrial yang lebih baik, yaitu matrial komposit. Tujuan penelitian dapat mengetahui pengaruh fraksi volume serat tandan kosong kelapa sawit dengan sifat mekanik, jenis patahan dan mencari komposisi fraksi volume yang terbaik. Metode penelitian yang di gunakan pencetakan penekanan fraski volume $4 \%, 6 \%$ dan $8 \%$ pengujian di lakukan kampus Politeknik Negeri Pontianak Kampus Kab. Sanggau. Penelitian telah mendapatkan hasil, dengan bertambahnya fraksi volume serat maka nilai kekuatan tarik yang di miliki spesimen fraksi volume serat $4 \%, 6 \%$, dan $8 \% 43.20 \mathrm{MPa}, 65.00 \mathrm{MPa}$, dan 86.12 MPa. Nilai regangan masing-masing pada fraksi volume $4 \%, 6 \%$, dan $8 \%$ yaitu $11.80 \%, 4.07 \%$ dan $4.68 \%$ dan tanpa serat $6.47 \%$ adanya pengaruh regangan komposit berpenguat serat tandan kosong kelapa sawit (TKKS) yakni pada fraksi volume $4 \%$ yakni $11.80 \%$. Komposit bepenguat serat tandan kosong kelapa sawit bisa di jadikan penguat pada komposit. Jenis patahan yang terjadi pada
\end{abstract}


spesimen resin polyster dan komposit berpenguat serat TKKS jenis patahan getas. Fraksi volume serat $6 \%$ yang di miliki modulus elastistas terbesar dengan nilai $43 \mathrm{MPa}$. Hasil ini mempengaruhi fraksi volume serat $4 \%$ dan $8 \% 2.66 \%$, dan $21.48 \%$ sedangkan tanpa serat tandan kosong kelapa sawit $8.79 \mathrm{MPa}$.

Kata kunci: Resin Polyster, komposit, serat tandan kosong kelapa sawit, uji tarik

\section{Pendahuluan}

Produk limbah dari kelapa sawit dari salah satu industri kelapa sawit yang dikenal sebagai tandan kosong kelapa sawit. Saat ini perkembangan teknologi bahan semakin berkembang pesat. Berbagai bahan telah dilakukan penelitian berlanjut untuk mendapatkan material yang lebih baik, yaitu material komposit. Kemampuan yang mudah dibentuk sesuai pada kebutuhan, sifat mekanik, aplikai penggunaan komposit sebagai bahan alternatif yang mampu menyamai material logam dan kayu, dan saat ini kayu sangat susah sekali untuk mendapatkannya pada berbagai produk yang dihasilkan oleh indutri manufaktur.

Bahan penguat (reinforcement) digunakan pada komposit, salah satunya serat. Komposit merupakan paduan matrik, yang mana serat sebagai penguatnya. Serat yang digunakan memiliki sifat mekanik diantaranya kekuatan tarik yang lebih kuat. Pemanfaatan serat tandan kosong kelapa sawit (TKKS) untuk produk yang bermanfaat dan mempunyai nilai jual.

Tujuan dari penelitian ini adalah mendapatkan proses pembuatan yang sesuai dengan kesamaan dengan kemampuan baja tulangan yang digunakan sebagai konstruksi bangunan, serta mendapatkan tegangan dan regangan struktur beton ringan yang diperkuat serart tandan kosong kelapa sawit dari pengaruh beban statik.

Pada generasi sekarang, komposit yang diperkuat dengan serat diakui sebagai salah satu material terpenting. Kinerja mekanis yang andal yang ditunjukkan oleh komposit Fiber-Reinforced Polymer (FRP) telah mendapatkan penerimaan besar karena sifatnya yang melekat seperti ketahanan tinggi terhadap korosi, kekuatan tinggi, dan rasio modulus-terhadap-berat dan ketahanan kelelahan yang ditingkatkan [1].
Cangkang kelapa sawit sebagai kmposit polimer termoplastik adannya pengkikatan karateristik komposit, sifat mekanik sebagai pengisi penguat seperti kekuatan tarik [2].

Komposit hidbrida epoksi yang diperkuat serat tandan kosong kelapa sawit dengan metode hand lay-up dengan lapisan berbeda dengan hasil sifat mekanik Tarik dan lentur menggunakan mesin universal testing hasil yang diperoleh bahwa kekuatan tarik komposit hibrida dipengaruh oleh lapisan komposit telah dijadikan sebagai bahan yang menjanjikan untuk aplikasi otomotif, dirgantara, dan konstruksi [3].

Serat tandan kosong kelapa sawit dan serat tebu dijadikan sebagai bahan dasar komposit di sektor bangunan yang ditentukan dengan beberapa penyerapan air, pengembangan ketebalan, densitas, kandungan rongga, ditemukan bahwa serat tebu kekuatan tarik dan modulus elastisitas 5,56 MPa dan $661 \mathrm{MPa}$ komposit ini dapat diterapkan sebagai bahan di dinding sebagai insulasi termal dan retensi panas dalam sektor bangunan dan kosntruksi dengan tujuan penghematan energi [4].

Komposit serat tandan kosong kelapa sawit yang merupakan limbah industri kelapa sawit, polikarprolakton (PCL dan Nikel Oksida (NiO) dengan metode koaksial ujung terbuka untuk rentang frekuensi gelombang mikro $0,2 \mathrm{MHz}$ komposit ini dapat mengubah rasio $\mathrm{PCL} / \mathrm{NiO} / \mathrm{OPEFB}$ untuk aplkiasi radio dan komunikasi dalam pembuatan antena, transmisi, dan komponen gelombang mikro lainnya [5].

Pemnafaatan limbah kelapa sawit sebagai dasar beton karena kandungan pozzolanya, hasilnya menujukkan potensi penggunaan POFA dalam produksi beton berbusa dengan penabahan 50\% POFA hanya sekitar $30 \%-40 \%$ berdasarkan kuat 
tekannya. Yang berpotensi sebagai bangunan ringan [6].

\section{Tinjauan Pustaka}

Pengembangan komposit polimer yang diperkuat serat gelas (GFRP) dengan matriks yang terdiri dari campuran polimer epoksi dan vinil ester. Jaringan polimer Interpenetrasi yang berevolusi (IPN) yang terbentuk karena pencampuran polimer menghasilkan sifat geser tarik, lentur, dan interlaminar yang lebih baik dari komposit hibrida dari pada komposit serat kaca / epoksi (GE) dan serat kaca / vinil ester (GVE) [7]. Matriks termoset seperti epoksi, vinil ester, dan poliester biasanya digunakan sebagai matriks polimer [8]. Sifat tarik, fisik, dan morfologi tandan kosong kelapa sawit / serat ampas tebu diperkuat komposit hibrida fenolik. Komposit serat alami serbaguna sangat diterapkan dalam konstruksi [4]. Berbagai penelitian menemukan komponen utama dalam bahan lignoselulosa seperti kandungan selulosa, hemiselulosa, dan lignin memiliki sifat yang unik untuk mendapatkan sifat mekanik dan fisik yang tinggi untuk pembuatan komposit polimer. Pada tahun 2012, Malaysia memiliki 5,08 juta hektar perkebunan kelapa sawit dan industri kelapa sawit menghasilkan sekitar 70 juta ton sisa tanaman biomasa [9].

Kelapa sawit (Elaeis guineensis) dibudidayakan di Malaysia sebagai tanaman pertanian dan menghasilkan bahan biomassa dalam jumlah besar terutama berupa serat dari batang, pelepah, mesocarp, cangkang sawit, dan tandan kosong [10]. Penyerapan air dan pembengkakan ketebalan tandan kosong kelapa sawit (TKKS) dan komposit rumput laut untuk mitigasi erosi tanah [11] kekuatan tarik dan lentur, pengukuran sudut serap air tanpa perlakuan dan perlakuan silang komposit serat alam yang diperkuat dengan nanopartikel silicon kekuatan tarik epoksi meningkat dari $8-9 \%$ saat meningkatkan nanopartikel [12]. Pati modifikasi glutardial dehyde dari limbah batang sawit sebagai bahan pengikat pembuatan komposit kayu [13].
Perlakuan permukaan terhadap sifat mekanik, fisik dan morfologi dari komposit fenolik yang diperkuat serat kelapa sawit / ampas tebu untuk aplikasi insulasi termal dinding perlakuan silane meningkatkan kinerja residu pertanian dan hibridisasi biokomposit berpotensi untuk mengembangkan kelas baru isolasi termal ramah lingkungan dan bahan bangunan dinding berkelanjutan [14].

\section{Metode Penelitian}

Metode penelitian komposit serat tandan kosong kelapa sawit adalah metode ekperimen diamana serat ini yang diambil dari limbah pabrik sawit yang masih berupa tandan, dan dilakukan penguraian serat secara manual selanjutnya dilakukan perendaman serat tandan kosong kelapa sawit dengan $\mathrm{NaOH}$ ini bertujuan untuk menghilangkan dari sisa-sisa minyak kelapa sawit, dan kotoran lainya adapun proses cetakan ini menggunakan cetakan kaca dengan sistem press.

Menentukan masa jenis serat tandan kosong kelapa sawit dengan menggunakan persamaan ;

$$
\rho=m / v
$$

Dengan :

$$
\begin{aligned}
& \rho=\text { massa jenis }\left(\mathrm{gr} / \mathrm{cm}^{3}\right) \\
& \mathrm{m}=\text { massa benda }(\mathrm{gr}) \\
& \mathrm{v}=\text { volume benda }\left(\mathrm{cm}^{3}\right)
\end{aligned}
$$

Komposisi serat tandan kosong kelapa sawit, resin, dan katalis berdasarkan volume cetakan dan prosentase komposisi yang dibutuhkan dengan menggunakan persamaan sebagai berikut :

Menghitung volume cetakan

$\mathrm{V}=\mathrm{P} \times \mathrm{L} \times \mathrm{t}$

Dengan :

$\mathrm{V}=$ volume $(\mathrm{cm} 3)$

$\mathrm{P}=$ panjang $(\mathrm{cm})$

$\mathrm{L}=$ lebar $(\mathrm{cm})$

$\mathrm{t}=$ tinggi $(\mathrm{cm})$

Benda Uji tarik Pengujian tarik penelitian menggunakan ukuran standar pengujian tarik yakni ASTM D638-14 type 1 pengujian tarik ini dilakukan di laboratorium Teknik Mesin Politeknik Negeri Pontianak Kampus Kab, Sanggau. 
Ukuran - ukuran spesimen dapat dilihat pada gambar 1 .

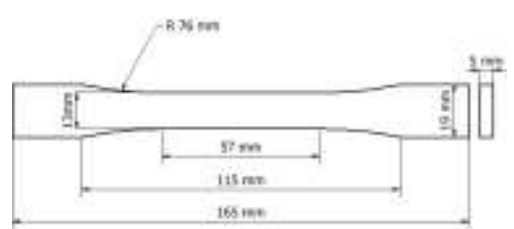

Gambar 1. Spesimen Uji Tarik ASTM D638-14

Regangan dapat didefinisikan sebagai perbandingan antara pertambahan panjang $(\Delta \mathrm{L}=$ Lu-Lo $)$ dengan panjang mula-mula Lo.

$$
\varepsilon=\frac{\Delta L}{L_{0}} \times 100 \%
$$

Tegangan nominal maksimum yang ditahan oleh batang uji sebelum patah disebut tegangan tarik, yaitu merupakan perbandingan antara beban maksimum yang dicapai selama percobaan tarik dan penampang mula-mula.

$$
\sigma_{R}=\frac{F_{\text {maks }}}{A_{0}}
$$

Tahapan penelitian disusun dalam berupa diagaram seperti pada gambar 2 .

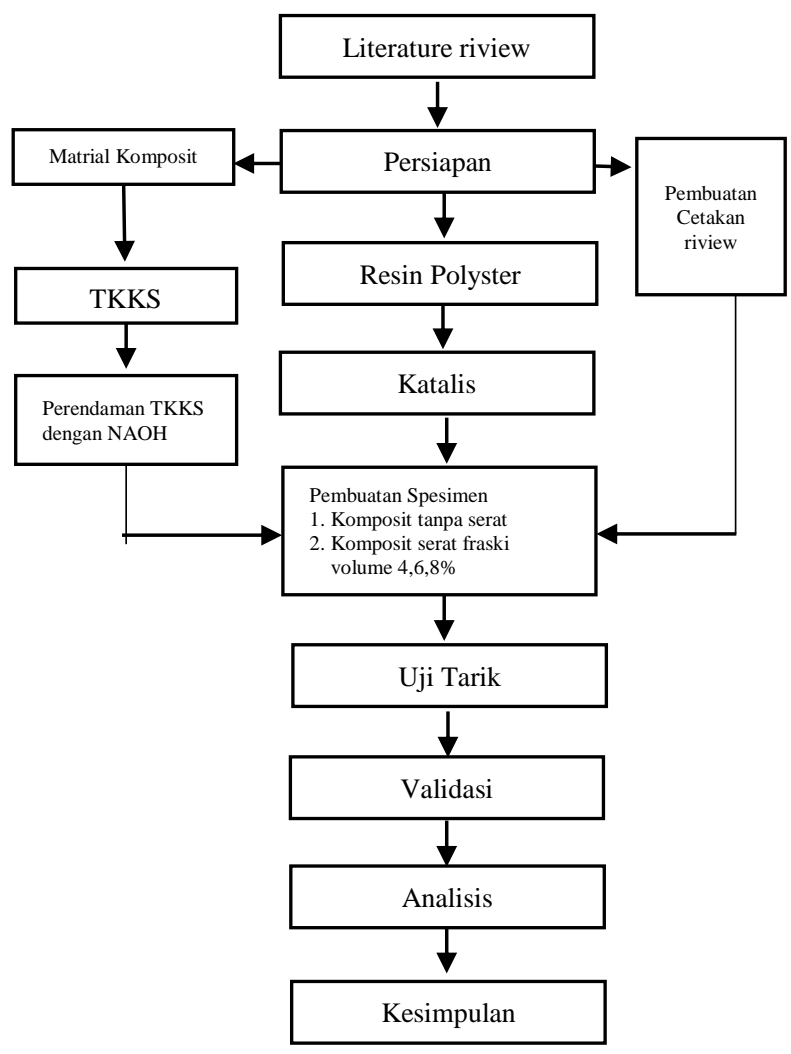

Gambar 2. Diagram alir Penelitian Pengaruh sifat mekanik dari fraksi volume komposit berpenguat serat TKKS

Tahapan proses pengujian yang di lakukan sebagai berikut :

1. Mencari literature review sebagai referensi penelitian

2. Menyiapkan bahan dan peralatan untuk pembuatan spesimen benda uji tarik sesaui standar ASTM D638-14

3. Proses pembuatan benda uji tarik 3 spesimen masing fraksi volume $4 \%, 6$ $\%$ dan $8 \%$. dan tanpa serat. Menggunakan cetakan kaca.

4. Proses pemotongan benda uji tarik sesuai ukuran standar ASTM D638-14.

5. Proses pengujian tarik masing-masing dari fraksi volume $4 \%, 6 \%$ dan $8 \%$.

6. Pengolahan data dari hasil pengujian Tarik

7. Menganalisa dari hasil pengolahan data kekuatan tarik, regangan, karakter patahan dari komposit serat tandan kosong kelapa sawit.

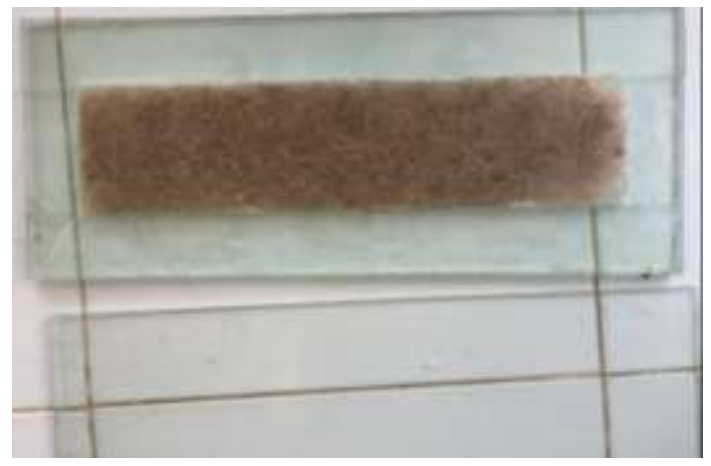

Gambar 3. Hasil dari cetakan Press Molding komposit serat tandan kosong kelapa sawit.

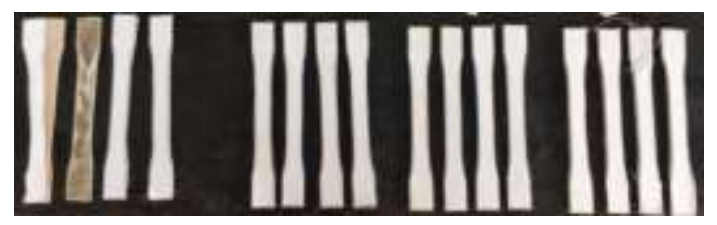

Gambar 4 Hasil Potongan benda uji Tarik ASTM D638-14

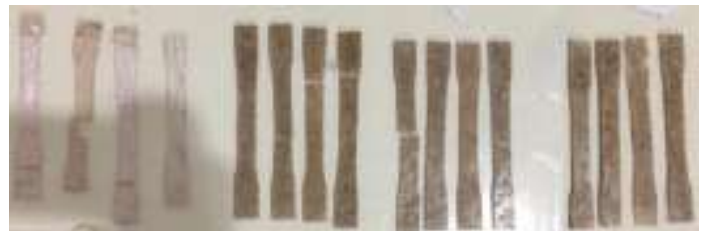

Gambar 5 Hasil setalah pengjian Tarik komposit tanpa serat, komposit fraksi volume $4 \%$, komposit fraksi volume $6 \%$, komposit fraksi volume $8 \%$. 


\section{Hasil dan Pembahasan}

Hasil uji tarik komposit serat tandan kosong kelapa sawit dari masing-masing fraksi volume $4 \%, 6 \%$ dan $8 \%$ dan tanpa serat dari 4 variasi pengujian ditampilkan dalam tabel 3 .

Tabel 3. Rata - rata kekuatan tarik, regangan, dan modulus elastisitas komposit tanpa serat dan serat TKKS

\begin{tabular}{ccccc}
\hline $\begin{array}{c}\text { Fraksi } \\
\text { Komposit }\end{array}$ & $\begin{array}{c}\text { Beban } \\
(\mathrm{kN})\end{array}$ & $\begin{array}{c}\text { Kekuatan } \\
\text { Tarik } \\
(\mathrm{MPa})\end{array}$ & Regangan & $\begin{array}{c}\text { Modulus } \\
\text { Elastisitas } \\
(\mathrm{MPa})\end{array}$ \\
\hline Resin & 5,1 & 78,00 & 5,26 & 14,83 \\
$4 \%$ & 2,8 & 43,00 & 6,76 & 6,36 \\
$6 \%$ & 5,4 & 83,00 & 1,9 & 43,68 \\
$8 \%$ & 5,6 & 86,00 & 2,7 & 31,85 \\
Asim.M 2018 & & 60,00 & 1 & 1,1 \\
\hline
\end{tabular}

Tabel 3 memperlihatkan bahwa hasil pengujian tarik kekuatan tarik tertinggi 86,12 $\mathrm{MPa}$ pada komposit serat tandan kosong kelapa sawit pada fraksi volume fraksi volume $8 \%$ dari rata-rata 4 pengujian.

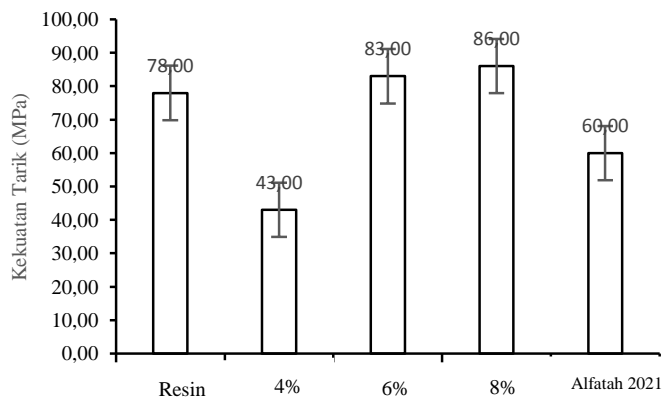

Gambar 6. Grafik kekuatan Tarik rata-rata Komposit tanpa serat dan Fraksi volume Serat TKKS ,Alfatah

[2]

Dari gambar 6. Nilai kekuatan tarik maksimum pada komposit serat TKSS dan tanpa serat yakni pada komposisi fraksi volume $8 \%$ dengan kekuatan tarik $86 \mathrm{MPa}$ sedangkan nilai minimum kekuatan tarik pada komposit serat TKSS yakni pada komposit fraksi volume $4 \%$. Dengan nilai kekuatan tarik $43 \mathrm{MPa}$. Dengan demikian tanpa serat mengalami peningkatan dengan kekuatan tarik $78 \mathrm{MPa}$, Hal ini membuktikan bahwa makin besar nilai fraksi volume pada kekuatatan tarik semakin meningkat akan mempengaruhi sifat mekanik kemampuan bahan terhadap kekuatan tarik.

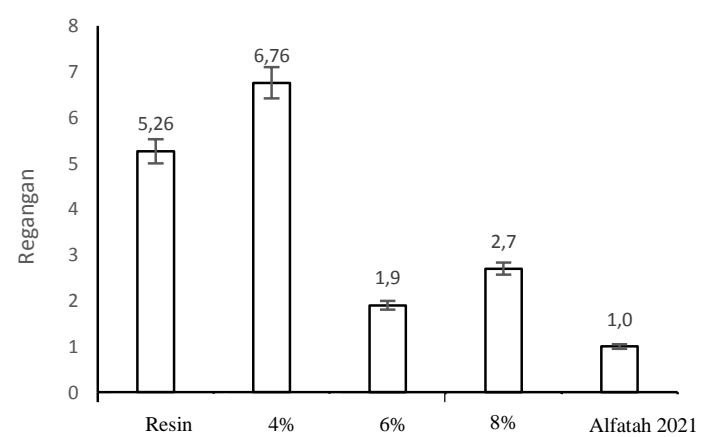

Gambar 7. Grafik Nilai regangan Komposit berpenguat serat TKKS dan Tanpa serat TKKS

Dari gambar 7, nilai regangan maksimum pada komposit serat TKSS dengan fraski volume 4\% yaknik 6,76 dan minimum di fraksi volume $6 \%$ yakni dengan nilai regangan 1,9 sedangkan resin tanpa serat 5,26 pengujian ini membuktikan regangan pada komposit tidak mempengaruhi banyaknya komposisi serat pada kemampuan bahan.

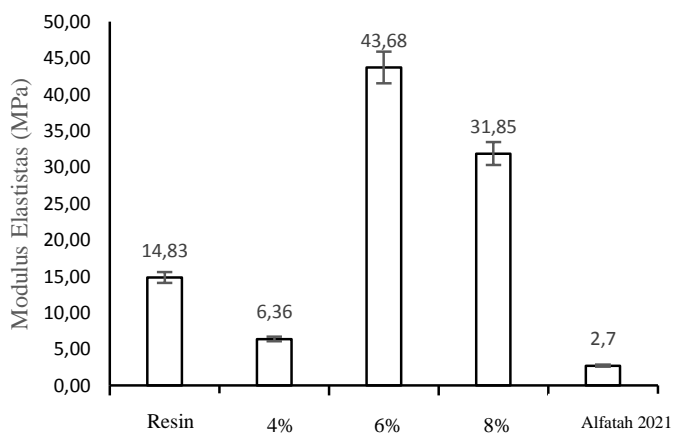

Gambar 8. Grafik Nilai Modulus Elastisitas Komposit Berpenguat Serat TKKS.

Dari gambar 8, pada grafik yang ditunjukkan dalam hasil pengujian tarik, nilai modulus elastisitas merupakan perbandingan antara tegangan nilai maksimum di fraksi volume $6 \%$ yakni 43,68 $\mathrm{MPa}$, sedangan nilai minimum ada di fraksi volume di fraksi volume $4 \%$ yakni 6,36 MPa. 


\section{Kesimpulan}

Dari hasil penelitian dapat disimpulkan bahwa makin besar nilai fraksi volume kekuatatan tarik semakin meningkat. Regangan pada komposit tidak mempengaruhi banyaknya komposisi serat pada kemampuan bahan.

\section{Referensi}

[1] S. Yashiro, D. Nakashima, Y. Oya, T. Okabe, and R. Matsuzaki, "Particle simulation of dual-scale $\mathrm{fl}$ ow in resin transfer molding for process analysis," Compos. Part A, vol. 121, no. February, pp. 283-288, 2019, doi: 10.1016/j.compositesa.2019.03.038.

[2] T. Alfatah, E. Marya, M. Syabriyana, and M. Dani, "Advances in oil palm shell fibre reinforced thermoplastic and thermoset polymer composites," Alexandria Eng. J., 2021, doi: 10.1016/j.aej.2021.09.061.

[3] K. A. M. Salleh and N. Saba, "Effects of layering sequence and gamma radiation on mechanical properties and morphology of Kevlar / oil palm EFB / epoxy hybrid composites," Integr. Med. Res., vol. 8, no. 6, pp. 5362-5373, 2019, doi: 10.1016/j.jmrt.2019.09.003.

[4] N. Azlina, M. Jawaid, E. Syams, S. Abdul, and K. Yamani, "Tensile , physical and morphological properties of oil palm empty fruit bunch / sugarcane bagasse fibre reinforced phenolic hybrid composites," Integr. Med. Res., vol. 8, no. 4, pp. 3466-3474, 2019, doi: 10.1016/j.jmrt.2019.06.016.

[5] A. Fahad, Z. Abbas, and M. Faiz, "Dielectric characterization of oil palm fiber reinforced polycaprolactone-nickel oxide composite at microwave frequency," Procedia Environ. Sci., vol. 30, pp. 273-278, 2015, doi: 10.1016/j.proenv.2015.10.049.

[6] A. Munir, "Utilization of palm oil fuel ash ( POFA ) in producing lightweight foamed concrete for nonstructural building material," Procedia Eng., vol. 125, pp. 739746, 2015, doi: 10.1016/j.proeng.2015.11.119.

[7] B. N. V. S. G. G. K, M. Maharudrayya, B. Chandra, and K. Prusty, "Improved mechanical responses of GFRP composites with epoxy-vinyl ester interpenetrating polymer network," Polym. Test., vol. 93, no. September 2020, p. 107008 , 2021, doi: 10.1016/j.polymertesting.2020.1070 08.

[8] A. L. Nazareth, S. C. S. Teixeira, A. C. C. Widal, and F. M. B. Coutinho, "Mechanical properties of polymer composites based on commercial epoxy vinyl ester resin and glass fiber," vol. 20, pp. 895-899, 2001.

[9] A. H. R. Aljuboori, "Oil palm biomass residue in Malaysia: Availability and sustainability Oil Palm Biomass Residue In Malaysia: Availability And Sustainability," no. January 2013, 2017.

[10] N. Abdullah and G. Town, "The Oil Palm Wastes in Malaysia The Oil Palm Wastes in Malaysia," no. December, 2013, doi: 10.5772/55302.

[11] M. K. M. Haafiz and M. I. Syakir, "Water Absorption and Thickness Swelling of Oil Palm Empty Fruit Bunch ( OPEFB ) and Seaweed Composite for Soil Erosion Mitigation Water Absorption and Thickness Swelling of Oil Palm Empty Fruit Bunch ( OPEFB ) and Seaweed Composite for Soil Erosion Mitigation," no. November, 2017, doi: 10.21315/jps2017.28.2.1.

[12] N. Parthipan and C. K. Ang, "Mechanical Strength and Water Absorption Analysis of Silane Treated Kenaf Natural Composites With Silicon Nanoparticles." 
[13] M. Hazim, M. Amini, R. Hashim, N. Syuhada, O. Sulaiman, and M. Ezwan, "International Journal of Adhesion and Adhesives Glutardialdehyde modified starch from waste oil palm trunks as a binder for wood composite making," Int. J. Adhes. Adhes., vol. 104, no. October 2020, p. 102757, 2021, doi: 10.1016/j.ijadhadh.2020.102757.

[14] N. R. K. $\quad$ Y. ZainudincSalmanAlameryd, "Effect of surface treatment on mechanical, physical and morphological properties of oil palm/bagasse fiber reinforced phenolic hybrid composites for wall thermal insulation application," Constr. Build. Mater., vol. 276, 2021, doi: https://doi.org/10.1016/j.conbuildma t.2020.122239. $10.2174 / 1573411013666171003154$ 410. 